Burkhardt, Stefan, Mit Stab und Schwert. Bilder, Träger und Funktionen erzbischöflicher Herrschaft zur Zeit Kaiser Friedrich Barbarossas. Die Erzbistümer Köln und Mainz im Vergleich

\title{
Waldemar Könighaus
}

\section{OpenEdition}

Journals

Édition électronique

URL : http://journals.openedition.org/ifha/2156

DOI : 10.4000/ifha.2156

ISSN : 2198-8943

Éditeur

IFRA - Institut franco-allemand (sciences historiques et sociales)

Référence électronique

Waldemar Könighaus, « Burkhardt, Stefan, Mit Stab und Schwert. Bilder, Träger und Funktionen erzbischöflicher Herrschaft zur Zeit Kaiser Friedrich Barbarossas. Die Erzbistümer Köln und Mainz im

Vergleich », Revue de l'IFHA [En ligne], Date de recension, mis en ligne le 01 janvier 2010, consulté le 22 septembre 2020. URL : http://journals.openedition.org/ifha/2156 ; DOI : https://doi.org/10.4000/ifha. 2156

Ce document a été généré automatiquement le 22 septembre 2020

(CIFHA 


\title{
Burkhardt, Stefan, Mit Stab und
} Schwert. Bilder, Träger und Funktionen erzbischöflicher Herrschaft zur Zeit Kaiser Friedrich Barbarossas. Die Erzbistümer Köln und Mainz im Vergleich

\author{
Waldemar Könighaus
}

1 Il est bien connu que les deux sièges métropolitains rhénans de Cologne et de Mayence constituaient les centres ecclésiastiques les plus importants de l'Empire. Il n'est donc guère étonnant que la recherche, depuis des siècles, se soit intéressée à de nombreux aspects de l'histoire de ces centres de pouvoir spirituels et temporels. Des approches inédites, pourtant, sont encore susceptibles d'apporter du nouveau. C'est ce que démontre la présente étude, forte de près de 780 pages et de 174 cartes et illustrations, thèse de doctorat présentée à l'Université de Heidelberg durant le semestre d'hiver 2006-2007.

2 Nommés dans le titre, la « crosse » et le « glaive » constituent les deux symboles les plus éminents d'un pouvoir double, à la fois spirituel et temporel. L'auteur s'emploie à élucider de quelle façon ce pouvoir était exercé et représenté dans les archidiocèses de Cologne et de Mayence et quels groupes en étaient les relais, et ce au temps du règne de Frédéric Barberousse. S.B. place au cœur de l'analyse le concept bourdieusien de capital et la nomenclature afférente, ce qui pourra de prime abord désarçonner l'historien. Dans le droit fil de P. Bourdieu, l'auteur fait siens les concepts de capital culturel, économique et symbolique, ajoutant à ce triptyque un capital « sacral »- ce par quoi il entend ici aussi bien le trésor des reliques que les canonisations, les processions et les édifices religieux; il les applique aux pontificats et aux pratiques du pouvoir des archevêques de Mayence Arnold von Selenhofen, Conrad von Wittelsbach et Christian 
von Buch, ainsi qu'à leurs homologues colonais Friedrich von Berg, Rainald von Dassel et Philipp von Heinsberg.

3 Après une introduction succincte, où l'auteur explicite la sociologie bourdieusienne ( $\mathrm{p}$. 14-17) avant de donner un bref état de la recherche, S.B. revient tout d'abord à grands traits sur les évolutions de la fonction épiscopale ainsi que sur la carrière de ses « héros " jusqu'à leur élévation à la dignité épiscopale. Dans un deuxième chapitre, l'auteur s'attache aux vecteurs et aux relais du pouvoir - pas seulement celui de l'archevêque : les différentes cours, les actes et leur langue - notamment les préambules -, les sources historiographiques, les sceaux et les monnaies sont ainsi examinés. L'analyse débouche dans le chapitre 3 sur la confrontation des images et des fonctions du pouvoir archiépiscopal, confrontation dont émergent plusieurs thèses fortes. À l'aide des outils qu'il s'est choisis, l'auteur parvient ainsi à mettre en évidence avec une netteté rarement atteinte les différences structurelles entre les deux sièges. La primauté de Cologne, en particulier pour ce qui est du capital sacral - reliques notamment -, apparaît en pleine lumière au terme de l'analyse. Le cas colonais et le cas mayençais convergent en revanche dans l'existence d'une certaine tension entre exercice des missions temporelles et spirituelles.

4 Aux conclusions succèdent, outre les habituelles bibliographies (sources et littérature secondaire), deux annexes imposantes : les résultats de l'analyse statistique portant sur les actes des archevêques d'une part, et les cartes et illustrations déjà signalées plus haut d'autre part. Les cartes, qui permettent de visualiser les structures des réseaux curiaux ainsi que la géographie des destinataires des actes (le lecteur trouvera quelques indications pour la lecture des cartes aux p. 89, 102-109 et 303-317), constituent un aspect innovant du travail.

$5 \mathrm{Au} v \mathrm{vu}$ du vaste corpus documentaire exploité par l'auteur dans son travail, il n'est guère surprenant de trouver au fil de l'étude un nombre assez élevé de coquilles, notamment dans les nombreuses citations latines. On relève également, ici ou là, quelques erreurs manifestes : ainsi Quedlinburg est-il un chapitre de chanoinesses et non une abbaye de religieuses augustines (p. 514). Ces petites bévues, qu'il convient de mettre en regard de la masse documentaire impressionnante, presque démesurée, que brasse l'auteur, n'enlèvent rien à la qualité d'un travail innovant, bien structuré, riche de résultats qui font progresser nos connaissances. L'avenir dira si l'introduction du concept sociologique de capital à l'horizon de la recherche historique fera école.

Waldemar Könighaus (Göttingen) 